\title{
Outbreak of Foodborne Botulism in Alexandria, Egypt: Modulating Indications for Administration of Heptavalent Botulinum Antitoxin
}

\section{Sara A Ghitani}

Faculty of Medicine of Alexandria University: Alexandria University Faculty of Medicine

\section{Maha A Ghanem}

Faculty of Medicine of Alexandria University: Alexandria University Faculty of Medicine

\section{Eman A Sultan}

Alexandria Medicine: Alexandria University Faculty of Medicine

Maram Atef ( $\triangle$ maramatef99@gmail.com )

Alexandria University Faculty of Medicine https://orcid.org/0000-0002-4646-1326

\section{Maii F Henaidy}

Faculty of Medicine of Alexandria University: Alexandria University Faculty of Medicine

\section{Research Article}

Keywords: Alexandria Poison Center (APC), Heptavalent botulinum antitoxin (HBAT), mild neurological sequelea

Posted Date: March 22nd, 2021

DOI: https://doi.org/10.21203/rs.3.rs-267943/v1

License: (c) (i) This work is licensed under a Creative Commons Attribution 4.0 International License. Read Full License

Version of Record: A version of this preprint was published at Environmental Science and Pollution Research on January 28th, 2022. See the published version at https://doi.org/10.1007/s11356-02118031-y. 


\section{Abstract}

Background: In October 2019, 94 patients were admitted into Alexandria Poison Center (APC) with a history of ingestion of Feseekh (salted fish). As a trial to allocate the resources, not all patients were given Heptavalent botulinum antitoxin (HBAT) immediately.

The current study aimed to portray the clinical characteristics of the cases, explore the possible relation between these characteristics and necessity of HBAT administration, explore the reliability of MLT, and to establish a clinical guide for management with preservation of resources.

Subject and Method: the current prospective study included 94 patients who were admitted to Alexandria Poison Center (APC) in the period from $29^{\text {th }}$ September to $27^{\text {th }}$ October 2019. The patients' data was recorded using a checklist that includes: personal data, past medical history, clinical assessment, investigations, treatment and the outcome. The checklist was carried out to assess and follow up each patient. Hospitalized patients were categorized according to symptoms consistent with botulism. The equine HBAT, made by Emergent BioSolutions Canada Inc. (formerly Can gene Corporation) was used in the treatment.

Results: HBAT was given to (36.2\%) patients only out of the total admission. However, $87.2 \%$ of patients were completely cured, whereas $10.6 \%$ of patients were discharged with mild neurological sequelea and death occurred only in two cases $(2.2 \%)$.

Conclusion: $63.8 \%$ of cases with suspected foodborne botulism toxicity could be managed by supportive treatment only with no need for HBAT.

\section{Introduction}

Botulism is considered one of the recurrent events that confront poison centers, in Egypt, each year due to a traditional salted fish meal which is consumed each spring (Weber et al.1993). In the spring of 2019, there were 58 cases of botulism admitted to APC and only 3 cases needed botulinum antitoxin. However, they suffered from side effects where 2 cases had severe epistaxis and one case arrested during antitoxin administration. On 29 September, a child was transferred to APC for differential diagnosis of paralytic ileus as her family said she was given a piece of salted fish (feseekh) and she was considered the first case of the outbreak. Preliminary assessment of the situation was carried out and preparations were made to confront a large outbreak out of season.

A collaborative team from APC doctors with Egyptian Ministry of Health $(\mathrm{EMOH})$ was initiated to conduct interviews with the cases about the source, the time of the start of symptoms, other personnel of same family exposed to same meal.... etc. Blood specimens were collected from the cases. Identified factors common to all cases and formulated preliminary hypotheses were issued. The team delivered a daily report to the authorities, and all types of media were used to issue a warning until the outbreak was stopped on 27-10-2019. The Egyptian news declared previously the death of almost 100 tons of "mullet" 
fish and veterinarians warning of the mass death of fish in a small town called Rashid which was considered the source of that outbreak (Veterinarians warn of the mass death of fish in Lake Rashid.2019).

Due to delay in results of mouse lethal test (MLT) and its positive and negative fallacies, the APC team treated the cases depending on the clinical picture (Lindstrom et al 2006, Chaudhry.2011, Wilder-Kofie et al. 2011, Wheeler et al.2009). We tried to decrease the exposure of the patients to the side effects of the antitoxin due to our unpleasant experience with Heptavalent botulinum antitoxin in spring of the same year. (Richardson et al 2020).

The current study aimed to portray the clinical characteristics of the cases, to explore the possible relation between these characteristics and necessity of HBAT administration, to explore the reliability of MLT and to establish a clinical guide of management of the suspected cases of botulism with preservation of resources.

\section{Subjects And Methods}

I. Research strategy and design: The descriptive epidemiological approach is selected.

\section{Research setting:}

Target population and place: All patients admitted to APC - The Main University Hospital, with history of salted fish (Feseekh) ingestion during the outbreak (94 cases)

Time: from 29 September to 27 October 2019

Ethical consideration: The approval of the Ethical Committee of the Faculty of Medicine for the present study was obtained.

\section{Research tools:}

A checklist and record review were carried out for collection of data to assess and follow up each patient. The equine Heptavalent Botulism Antitoxin (A, B, C, D, E, F, G), made by Emergent BioSolutions Canada Inc. (formerly Can gene Corporation) was used in treatment. ${ }^{(8)}$

Mouse Bioassay for Clostridium botulinum toxin was performed following FDA's Bacteriological Analytical Manual.

\section{Categorization of patients:}

Clinical assessment was completed to all cases and a checklist including different signs and symptoms of botulinum toxicity was fulfilled on admission. 
To properly manage the resources, the patients were classified into the groups according to their clinical assessment that was repeated everyone hour. If the signs and symptoms were improving, assessment follow up would be every 6 hours.

The patients' groups were as the following:

Group A: included those with history of Feseekh ingestion and were completely normal on their first assessment and throughout their hospital stay ( 3 cases).

Group B: included patients complained of typical gastroenteritis throughout their course i.e., nausea, vomiting, diarrhea, abdominal pain, and mild abdominal distention (38 cases).

Group C: included all cases who developed neurological or autonomic dysfunction symptoms whether GIT symptoms were present or not. They were further subdivided into two groups:

1. Group C1: those at time of admission presented with evident serious neuromuscular dysfunction signs as ptosis, peripheral muscle weakness or hypoventilation ( 20 cases).

2. Group C2: those at time of admission presented with mild cranial nerve deficit manifestations as dilated fixed pupil \&/or blurring of vision, dry mouth \&/or mild dysphagia, mild dysphonia and patients complained of constipation \&/or severe abdominal distention were further classified according to their disease course into:

Patients with progressive course whose signs increased in severity or who developed evident neuromuscular dysfunction signs or any other cranial deficit within 24 hours of observation. (14 cases)

Patients with stationary course who did not develop any additional neuromuscular paralysis signs during their period of observation. (19 cases)

\section{Method of statistical analysis:}

The data were collected and stored into a computer. Statistical analysis was done using Statistical Package for Social Sciences (SPSS/version 20) software. Data was presented as numbers and percentages for categorical variables and mean \pm standard deviation (SD) for continuous variables. For testing associations between qualitative variables, the chi square test was used. Significance of the obtained results was judged at the $5 \%$ level.

\section{Results}

\section{Demographic data:}

The highest percentage of the participated cases (42.6\%) were in the age group $20-<40$ years. This was followed in a descending manner by the age group $<20$ years (34\%), then the age group of $40<60$ years $(21.3 \%)$ and the age group $\geq 60$ years $(2.1 \%)$. More than two thirds $(69.1 \%)$ were females while $30.9 \%$ 
were males. As regard residence, $36.2 \%$ of the cases were from Alexandria, $35.1 \%$ came from Kafr ElSheikh, $27.6 \%$ were from Elbehira and only one case (1.1\%) was living in Al-Ismailia.

\section{Past medical history:}

In the current study, medical history of previous diseases, injuries and operative procedures were taken from all participants. However, most of the studied patients (91.5\%) had no history of chronic diseases.

\section{History of salted fish (Feseekh) ingestion:}

All the participated cases presented to the hospital from six hours to nine days after Feseekh ingestion with a mean value of $1.70 \pm 1.49$ days.

\section{Assessment of the cases:}

The most common findings observed in admitted patients were nausea and vomiting (76.6\%), abdominal distension (41.5\%) and dilated fixed pupil (29.8\%). (Table 1)

\section{Administration of HBAT:}

All cases with serious evident neurological signs either at time of admission or during observation received HBAT immediately. They were Thirty-four patients (36.2\%). The first dose of HBAT was given through 0.33 - 6 days from Feseekh intake. Among those who received the first dose of HBAT, more than half $(55.9 \%)$ of the cases improved completely. On the other hand, six patients $(17.7 \%)$ showed no improvement with persistent symptoms and 9 cases (26.4\%) showed temporary improvement followed by relapse. Those fifteen patients were given the second vial of the HBAT. The time interval between the first and second vials was 1-4 days with a mean of $2.03 \pm 0.93$ days. Only one patient needed a third vial of the botulinum antitoxin. This was attributed to the persistence of hypoventilation one day after the second dose.

The patients in group $\mathrm{C} 2$ were further categorized according to the number of mild cranial deficit complains and the need for HBAT administration and the results revealed that:

All patients who admitted to hospital complaining of only one symptom of autonomic dysfunction did not need the antitoxin, while $100 \%$ of patients presented with four autonomic symptoms needed the antitoxin during their period of observation. On the other hand, $77.8 \%$ of those with three autonomic dysfunction symptoms needed the antitoxin. However, half of those with only two autonomic symptoms developed neurological signs later and needed the antitoxin. And this difference is statistically significant with $p<0.001$. (Table 2)

\section{Result of mouse bioassay test:}

A blood sample was withdrawn from patients on admission to the poison center even after days of ingestion time of the Feseekh and serum was prepared and transferred to the lab. Mouse bioassay test 
was carried out to 82 out of 94 cases and $87.8 \%$ was negative. It means that 24 cases with negative mouse bioassay test developed neurological symptoms and needed HBAT. (Table 3 )

\section{Duration of hospitalization, ICU admission and need to mechanical ventilation support:}

The duration of hospital admission was 1-12 days with a mean of $3.71 \pm 2.75$ days. Moreover, 30 patients (31.9\%) admitted to ICU for a period ranged from 1-8 days with a mean of $3.40 \pm 1.81$ days. Eight patients (26.7\%) from group C1 needed mechanical ventilation for a period of 1-5 days with a mean of $2.50 \pm 1.60$ days.

\section{The outcome:}

Recovery was the major outcome (87.2\%) whereas neurological sequalae were present in $10.6 \%$ of patients -in the form of persistent constipation, distention, dry mouth with a very mild dysphagia and death occurred only in two cases $(2.2 \%)$.

\section{Discussion}

On spring, Egyptians' celebration of eastern festival is accompanied with eating Feseekh (salted fish). However, unexpected outbreak occurred in Autumn and it was justified by contamination of marine mullet meat during that time, where some of those contaminated fish were taken by some individuals and salted in their homes. (Veterinarians warn of the mass death of fish in Lake Rashid 2019).

The outbreak started with a 1.5-year-old child referred from Pediatric University Hospital to APC for differential diagnosis. She presented with paralytic ileus that raised the suspicion of intussusception and surgical abdomen. On examination the surgical emergency was eliminated. A similar scenario was mentioned by Spini et al (2015).

Due to the unusual young age of the child with the absence of the common paralytic manifestations of botulism, pediatricians doubted botulism. Pisani et al (2009) had explained a similar situation as the initial symptoms of the disease are often like several diseases and therefore differential diagnosis is very difficult and rarely suspected by the pediatrician.

Although the highest percentage of the patients were in the middle age group ( $20-<40$ years), extremes of age were also involved, and females outnumbered males. This could be explained by the Egyptian culture where the ladies prepared the meals to the families as well as tasting it before meals. All family members gathered for celebration and ate the same food so different ages are usually affected.

APC is serving Alexandria and all-around governorates (Elbehira, Kafr el-Sheikh, Marsa Matrouh, etc.). As the accident of contamination of the mullet fish meat occurred in Elbehira governorate so, all patients were directed to APC as in all other poisons. 
In the current work, $91.5 \%$ of the cases had no previous medical or surgical history. Past medical and surgical history was taken to exclude neurological diseases, previous stroke, and other gastrointestinal problems. All patient's symptoms started to appear after eating the Feseekh meal. All the participated cases presented to the hospital from six hours up to nine days after Feseekh ingestion with a mean of $1.70 \pm 1.49$ days. In their systematic review, Fleck-Derderian et al (2017) reported a median duration between exposure and symptom onset as approximately one day. This difference is expected due to the long incubation period of foodborne botulism which would reach up to 16 days.

The mouse lethal test (MLT) is the standard procedure for detection of botulism. Mouse bioassay test was carried out to 82 out of 94 cases. The results delivered several days after the clinical diagnosis revealed that $87.8 \%$ of cases were negative despite presence of clinical neurological manifestations. These negative results could be explained by the long period between the Feseekh ingestion and the withdrawal of serum sample as the samples were obtained from patients at the time of admission and many patients admitted to hospital few days after the appearance of symptoms. This result is in accordance with Temeri et al (2011) who stated that many clinical specimens have low levels of toxin which may not be evident within 4 days.

Although the clinical syndrome of botulism is distinctive, it needs a high index of suspicion to be diagnosed. In the current study, patients were presented with mydriasis (29.8\%), blurred vision (14.9\%), ptosis $(11.7 \%)$, dysphagia (24.5\%) and muscle weakness in $21.3 \%$ of patients. This is in accordance with Gaware et al (2011) who reported these symptoms as the classic for botulism.

On contrary to most of previous studies on Botulism that recommend early antitoxin administration to reduce mortality Gaware et al (2011), Kongsaengdao et al (2006) and Yu (2015). The current study aimed to manage the resources and to decrease the exposure of the patients to the side effects of the unnecessary administration of antitoxin. Thus, the patients in current study were classified at the time of admission into three groups. Only twenty patients -group C1- who presented with severe evident neurological symptoms; ptosis, muscle weakness or respiratory muscle affection with hypoventilation were given the BAT immediately. While the rest of patients didn't receive the BAT immediately but they were put under close observation.

Patients in group A who presented to hospital with just a history of Feseekh ingestion as members of their family ate the same meal and developed botulism manifestations and also patients in group B who presented with only gastroenteritis didn't develop any additional symptoms during their period of hospitalization and did not need to receive the BAT. Moreover, patients in group C2 who presented with mild cranial deficit didn't receive the BAT immediately as most of cranial deficits complain of patients in group $\mathrm{C} 2$ might be just a subjective feeling due to the fear or anxiety that result from the warnings spread at that time on the media or due to their affection by other patients in the outbreak.

However, in order to identify patients likeliest to benefit from the antitoxin treatment, patients in group C2 were categorized according to the number of cranial deficit signs on initial assessment to anticipate the 
deterioration and to predict who would need the antitoxin administration which may be valuable for further development of guidelines. The initial assessment of cases with suspected food-born botulism is very important.

In our opinion, this classification reduced the unnecessary administration of the HBAT to 60 patients who were managed by supportive treatment only. This protocol helped avoidance of many side effects of the antitoxin including the most severe ones as anaphylaxis and hypersensitivity reactions and other delayed allergic reactions as serum sickness. Schussler et al (2017) reported anaphylactic reactions in $1 \%-2 \%$ of botulinum antitoxin recipients that would be severe enough and necessitate intensive care.

Also, this is very important for prioritizing antitoxin treatment when its availability is limited especially in outbreaks where the number of patients is large and unpredicted. This was contradictory to O'Horo et al (2017), in their systematic review, as they could not identify patients likeliest to benefit from the antitoxin treatment. But this was in agreement with Anderson et al (2019) and Barker et al (2019).

In addition, after receiving the first dose of HBAT, (17.7\%) of the cases showed no improvement and (26.4\%) showed temporary improvement and relapsed later which necessitated the administration of further HBAT doses. These results may be explained by the mechanism of HBAT; it interacts only with unbound toxin, patients who admitted early were improved on one vial, while those arrived late needed second and third vials and 2 of them died in the hospital. (O'Horo et al 2017; Anderson et al 2019; Barker et al 2019). Those who suffered rebound after initial improvement were mentioned in a study of Fagan et al (2011).

The only drawback of the current protocol is prolongation of hospitalization due to monitoring of the patients which reaches up to 12 days in some cases to avoid missing the unpredicted side effects of the antitoxin.

Following the theory in current study, complete recovery occurred in (87.2\%). Complications were present in $10.6 \%$ of patients while death occurred only in two cases $(2.2 \%)$. All those $10.6 \%$ of patients who discharged with complications received the HBAT. They complained of persistent dry mouth with a very mild dysphagia not interfering with fluid, solid or semisolid food ingestion. Some complained of constipation which improved also with the usage of laxatives. This is like Gottlieb et al (2007) who concluded that previous symptoms of cholinergic autonomic blockade that are prominent during botulism as dry mouth would persist for a long-term later.

Regarding the two cases who died, both were in group $\mathrm{C} 1$ with evident neurological paralysis, they received the antitoxin, and both were in need for mechanical ventilation in ICU. They arrested in the ICU; one after 2 days and the other after 4 days without receiving any further doses of HBAT. According to the critical care physicians the cause of death was a superadded chest infection. This point is very important as the appropriate supportive care is still the cornerstone in recovery and survival after botulism. As those cases suffered respiratory compromise so a high-quality intensive care is needed. This is in accordance with Sheth et al (2008). 


\section{Conclusions}

Evidence based from that research that the course of cases with suspected botulism often has a stationary course and $63.8 \%$ of cases could be managed by supportive treatment with no need for HBAT, so we advise to keep the patient under close observation instead of rushing to give the anti-botulinum antitoxin, so we can protect him from the side effects of HBAT and manage resources at the same time especially in outbreaks. However, in evident neurological manifestations HBAT administration should be administered immediately.

\section{Declarations}

\section{Author's contribution:}

Sara A ghitani participated in the design of the study, drafted the manuscript, and participated in reviewing its final version, Maha $A$ Ghanem participated in data collection and in drafting the manuscript and reviewing the final version, Eman A Sultan participated in the design of the study and performed the statistical analysis, Maram Atef participated in data collection and storage and reviewing the final version and Maii $\mathrm{F}$ Henaidy participated in writing the results section.

\section{Funding}

The authors received no financial support for this research, authorship, and/or publication of this article.

\section{Availability of data and materials}

The authors confirm that the data supporting the findings of this study are available within the article [and/or] its supplementary materials.

\section{Compliance with ethical standards}

Competing interests None of the authors have any competing interests in the manuscript.

Ethics approval and consent to participate: Approval was obtained from the Research Ethics Committee of Faculty of Medicine, Alexandria University (IRB NO:00012098, FWA NO: 00018699, serial protocol NO:0304565).

Adherence to national and international regulations The Ethics Committee is constituted and operates according to ICH GCP Guidelines and applicable local and institutional regulations and guidelines that govern ethics committees' operation.

Consent for publication: Not applicable as the research didn't include any individual person's data in any form.

\section{References}


1. Anderson DM, Kumar VR, Arper DL, Kruger E, Bilir SP, Richardson JS. Cost savings associated with timely treatment of botulism with botulism antitoxin heptavalent product. PloS One. 2019;14(11): e0224700.

2. Barker D, Gillum KT, Niemuth NA, Kodihalli S. Therapeutic efficacy of equine botulism heptavalent antitoxin against all seven botulinum neurotoxins in symptomatic guinea pigs. PLoS One. 2019;14(9): e0222670.

3. Chaudhry R. Botulism: A Diagnostic Challenge. Indian J Med Res. 2011;134(1):10-2.

4. Fagan RP1, Neil KP, Sasich R, Luquez C, Asaad H, Maslanka S et al. Initial recovery and rebound of type $\mathrm{f}$ intestinal colonization botulism after administration of investigational heptavalent botulinum antitoxin. Clin Infect Dis. 2011 Nov;53(9): e125-8.

5. Fleck-Derderian S, Shankar M, Rao AK, Chatham-Stephens K, Adjei S, Sobel J et al. The Epidemiology of Foodborne Botulism Outbreaks: A Systematic Review. Clin Infect Dis. 2017;66(suppl_1): S73-S81. DOI: $10.1093 /$ cid/cix846.

6. Gaware VM, Kotade KB, Dolas RT, Dhamak KB, Somawanshi SB, Nikam VK. Botulism Foodborne Disease: A Review. J Chem Pharm Res. 2011;3(1):84-92.

7. Gottlieb SL, Kretsinger K, Tarkhashvili N, Chakvetadze N, Chokheli M, Chubinidze M et al. Long-term Outcomes of 217 Botulism Cases in the Republic of Georgia. Clin Infect Dis. 2007; 45 (2): 174-80.

8. Kongsaengdao S, Samintarapanya K, Rusmeechan S, Wongsa A, Pothirat C, Permpikul C et al.; Thai Botulism Study Group. An outbreak of botulism in Thailand: clinical manifestations and management of severe respiratory failure. Clin Infect Dis. 2006; 43:1247-56.

9. Lindstrom M, Korkeala H. Laboratory Diagnostics of Botulism. Clin Microbiol Rev. 2006;19(2):298314. DOI: 10.1128/CMR.19.2.298-314.2006

10. O'Horo JC, Harper EP, El Rafei A, Ali R, DeSimone DC, Sakusic A et al. Efficacy of Antitoxin Therapy in Treating Patients with Foodborne Botulism: A Systematic Review and Meta-analysis of Cases, 19232016. Clin Infect Dis. 2017;66(suppI_1): S43-S56.

11. Pisanti R, Vitiello R, Formicola S, Pisanti A. Infant Botulism Mimicking an Acute Abdomen. Infez Med. 2009;17 (4): 254-6.

12. Richardson JS, Parrera GS, Astacio H, Sahota H, Anderson DM, Hall C, Babinchak T. Safety, and clinical outcomes of an equine-derived heptavalent botulinum antitoxin treatment for confirmed or suspected botulism in the United States. Clin Infect Dis. 2020;70(9):1950-1957. DOI: 10.1093/cid/ciz515.

13. Schussler E, Sobel J, Hsu J, Yu P, Meaney-Delman M, Grammer LC et al. Workgroup Report by the Joint Task Force Involving American Academy of Allergy, Asthma \& Immunology (AAAAI); Food Allergy, Anaphylaxis, Dermatology and Drug Allergy (FADDA) (Adverse Reactions to Foods Committee and Adverse Reactions to Drugs, Biologicals, and Latex Committee); And the Centers for Disease Control and Prevention Botulism Clinical Treatment Guidelines Workgroup-Allergic Reactions to Botulinum Antitoxin: A Systematic Review. Clin Infect Dis. 2017; 66 (suppl_1): S65-S72. 
14. Sheth AN, Wiersma P, Atrubin D, Dubey V, Zink D, Skinner G et al. International outbreak of severe botulism with prolonged toxemia caused by commercial carrot juice. Clin Infect Dis. 2008; 47:124551.

15. Spini RG, Ferraris V, Glasman MP, Orofino G, Casanovas A, Debaisi G. Intussusception in infant with diagnostic botulism: A case report. Arch Argent Pediatr. 2015;113(5): e286-9. DOI: 10.5546/aap. 2015.e286.

16. Veterinarians warn of the mass death of fish in Lake Rashid. Thursday 26/ September/201906:13PM https://translate.google.com/translate? $\mathrm{hl}=\mathrm{en} \& \mathrm{sl}=\mathrm{ar} \& \mathrm{u}=\mathrm{https}: / / \mathrm{www} . \mathrm{el} b a$ ad.news/3995937\&prev=search

17. Weber JT, Hibbs RG Jr, Darwish A, Mishu B, Corwin AL, Rakha M et al. A massive outbreak of type E botulism associated with traditional salted fish in Cairo. J Infect Dis. 1993;167(2):451-4. DOI: 10.1093/infdis/167.2.451.

18. Wheeler C, Inami G, Mohle-Boetani J, Vugia D. Sensitivity of Mouse Bioassay in Clinical Wound Botulism. Clin Infect Dis. 2009;48(12):1669-73. DOI: 10.1086/599029.

19. Wilder-Kofie TD, Lúquez C, Adler M, Dykes JK, Coleman JD et al. An Alternative in Vivo Method to Refine the Mouse Bioassay for Botulinum Toxin Detection. Comp Med. 2011;61(3):235-42.

20. Yu P. Heptavalent botulinum antitoxin (BAT) use in patients treated under CDC's expanded access IND, 2010-2013. Atlanta, GA: CDC, 2015.

\section{Tables}

Table (1): Distribution of studied patients' group according to clinical assessment on admission $(n=94)$ 


\begin{tabular}{|c|c|c|}
\hline Clinical assessment & No. & $\%$ \\
\hline \multicolumn{3}{|l|}{ Ocular } \\
\hline Blurred vision & 14 & 14.9 \\
\hline Ptosis & 11 & 11.7 \\
\hline Mydriasis & 28 & 29.8 \\
\hline \multicolumn{3}{|l|}{ Bucco-pharyngeal } \\
\hline Dry mouth & 14 & 14.9 \\
\hline Dysphagia & 23 & 24.5 \\
\hline Dysphonia & 3 & 3.2 \\
\hline \multicolumn{3}{|l|}{ Digestive } \\
\hline Abdominal pain & 7 & 7.4 \\
\hline Constipation & 24 & 25.5 \\
\hline Distention & 39 & 41.5 \\
\hline Diarrhea & 13 & 13.8 \\
\hline Nausea \& vomiting & 72 & 76.6 \\
\hline Muscle weakness & 20 & 21.3 \\
\hline \multicolumn{3}{|l|}{ Grade: } \\
\hline II & 2 & 2.1 \\
\hline III & 1 & 1.1 \\
\hline IV & 17 & 18.1 \\
\hline \multicolumn{3}{|l|}{ Respiratory } \\
\hline Dyspnea & 12 & 12.7 \\
\hline Gasping & 1 & 1.1 \\
\hline Respiratory distress & 1 & 1.1 \\
\hline
\end{tabular}

Table (2): Relation between mild cranial deficit signs and administration of anti-toxin $(n=33)$ 


\begin{tabular}{|lllll|}
\hline Statistical significance & Total & \multicolumn{2}{l}{ Anti-toxin } & Number of mild cranial deficit signs \\
\cline { 2 - 5 } & & No & Yes & \\
\hline 14 & $14(100.0 \%)$ & $0(0.0 \%)$ & 1 \\
\hline 6 & $3(50.0 \%)$ & $3(50.0 \%)$ & 2 \\
\hline PC $=<0.001^{*}$ & $2(22.2 \%)$ & $7(77.8 \%)$ & 3 \\
\hline 9 & $0(0.0 \%)$ & $4(100.0 \%)$ & 4 \\
\hline 33 & $19(57.6 \%)$ & $14(42.4 \%)$ & Total \\
\hline
\end{tabular}

* Minor cranial deficit signs include:

- Dilated fixed pupil \&/or blurred vision

- Mild dysphagia \& / or dry mouth

- Mild dysphonia

- Constipation \&/or abdominal distension

- Feeling of dyspnea without any signs of respiratory distress

Table (3): Distribution of the studied cases according to mouse bioassay test $(n=82)$

\begin{tabular}{|lll|}
\hline Mouse bioassay technique $(\mathbf{n}=\mathbf{8 2})$ & No. & $\%$ \\
\hline Negative & 72 & 87.8 \\
\hline Positive & 10 & 12.2 \\
\hline
\end{tabular}

